\title{
The impact of low-carbon emission reduction policies on economic growth
}

\author{
Yuqi Sheng $^{1 *}$ \\ ${ }^{1}$ Accounting Department of Beijing Jiaotong University, Haidian District, Beijing, China
}

\begin{abstract}
As the development of a green and low-carbon economy has received great attention from governments around the world, carbon peaking and carbon neutrality have become important issues raised by China. As a major energy consuming country, government has actively formulated and implemented various carbon emission reduction policies in order to curb carbon emissions. Whether these policies achieve economic growth in the process of energy conservation and emission reduction, and promote China's green and low-carbon development transition is the focus of this paper. This paper selects data from 30 provinces in China from 2010 to 2019 , establishes a model, and empirically analysis the impact of carbon emission reduction policy tools on economic growth. The results show that there is a significant negative correlation between mandatory carbon emission reduction policies and economic growth, while market-based carbon emission reduction policies enhance the economic strength of the region. In addition, this paper empirically tests that after the establishment of the carbon market in 2013, market-based carbon emission reduction policies have significantly promoted economic growth, and the impact of carbon emission reduction policies on economic growth have regional heterogeneity.
\end{abstract}

\section{Introduction}

Greenhouse gas emissions have led to global warming and environmental degradation, which have severely threatened economic growth and the sustainable development of society and the environment. In order to cope with climate change and promote the reduction of greenhouse gases, mainly carbon dioxide, has become a top priority for all countries in the world. For this reason, the United Nations and governments of all countries have proactively adopted various policies and measures to alleviate climate problems. In 2020, the Chinese government proposed at the 75th United Nations General Assembly that "China will increase its nationally determined contributions, adopt more policies and measures, and strive to reach a peak in carbon dioxide emissions by 2030 , and strive to achieve carbon neutrality by 2060." The 2021 State Council government work report pointed out that it is necessary to do a solid job of carbon peaking and carbon neutrality, formulate an action plan for peak carbon emissions before 2030, and optimize the industrial structure and energy structure.

At this stage, China mainly adopts a parallel carbon emission reduction policy that mainly reduces carbon emissions per unit of GDP, supplemented by a carbon emission trading mechanism. The former is the government's mandated policy tool, and the latter is a market policy tool for voluntary emission reduction. Two different types of policy tools constitute the more effective carbon emission reduction measures currently implemented on the market in China. In the specific process of implementing carbon emission reductions, the state and enterprises increase investment in science and technology, guide and encourage technological innovation, and the industrial structure is constantly changing, which has a certain impact on China's economic growth. Therefore, studying the relationship between carbon emission reduction policies and economic growth and whether different types of carbon emission reduction policies have the same impact on economic growth has important practical significance for achieving the goal of coexisting carbon emission reduction and economic growth.

This paper used panel data from 30 provinces across the country from 2010 to 2019 as a sample to explore the impact of different carbon emission reduction policy tools on economic growth. Then provide theoretical support for the formulation and implementation of China's carbon emission reduction policies.

\section{Literature review}

OECD summarizes carbon emission reduction policy tools, which mainly include command-and-control regulation, economic or market mechanisms, persuasive methods, and moral preaching methods. ${ }^{[1]}$

Scholars have conducted research on the impact of carbon emission policies from a micro and macro perspective. At the micro level, Ge Yujie et al. ${ }^{[2]}$ showed that the reduction of energy consumption and emission levels of enterprises has a positive effect on financial performance. At the macro level, Zhang et al. ${ }^{[3]}$

\footnotetext{
* Corresponding author: syq199899@163.com
} 
showed that energy-saving and emission-reduction policies have significantly improved urban ecoefficiency. Zhang Guoxing et al. ${ }^{[4]}$ discussed the financial measures and guiding measures in the energy conservation and emission reduction policies have a significant promotion effect on the adjustment and upgrading of the industrial structure. Ding Lili et al. ${ }^{[5]}$ found that carbon emission rights trading policies can encourage companies to invest in emission reduction technology innovation.

\section{Hypothesis}

This paper divides carbon emission reduction policy tools into two categories: Mandatory policy tools and market policy tools. Due to China's vast territory and significant differences in economic, technological innovation, technological level and industrial structure between regions, different policy tools may have different effects on economic growth.

Mandatory policy tools mainly include the carbon dioxide emission target set by the government, which directly sets specific requirements for the regional carbon emission, and enterprises need to control the carbon emission level in accordance with the emission standards. For this reason, enterprises must increase investment in scientific and technological innovation to reduce emissions, occupying enterprise development funds, increasing costs and expenditures, resulting in a decline in profits and inhibiting economic growth. Therefore, the paper comes up with the hypothesis 1 :

H1: Mandatory carbon emission reduction policies restrain economic growth.

Unlike mandatory carbon emission reduction policies, market-based carbon emission reduction policies show voluntary nature and demonstrate corporate social responsibility. The market-based policy tools mainly include the carbon emission rights trading mechanism, through which the government sends carbon emission rights quotas to enterprises, stipulates the upper limit of carbon dioxide emissions for enterprises, requires enterprises to implement total management and emission reduction of their carbon emissions, and set penalties for excessive emissions.

According to their own costs, companies can independently reduce emissions through strategic adjustments, improved business models, low-carbon technological innovations, and optimized product development, or they can directly purchase allowances from the market to offset excess emissions. This policy tool uses the market mechanism to promote the independent emission reduction of carbon-emitting companies, and through market signals to urge and guide companies to reduce emissions, to minimize the cost of emission reduction, so the government and enterprises have a strong awareness of reducing carbon emissions and promote low carbon emissions. The development of the carbon industry contributes to economic growth. Therefore, hypothesis 2 of this paper is proposed:

$\mathrm{H} 2$ : Market-based carbon emission reduction policies promote economic growth.

\section{Research design}

\subsection{Sample selection}

I choose 30 provinces across the country from 2010 to 2019 (excluding Hong Kong, Macau, and Taiwan; Tibet is excluded because there is no energy consumption data), and select energy consumption, per capita GDP, industrial pollution control investment, industry output, R\&D expenditure, secondary industry GDP, import and export trade volume and population data.

\subsection{Variable definition}

\subsubsection{Dependent variable}

Economic growth (denoted as $\mathrm{G}$ ), which is measured by the natural logarithm of the per capita GDP of each province.

\subsubsection{Independent variable}

I divide carbon emission reduction policies into two different types: One is mandatory policy tool (denoted as P1) is measured by carbon dioxide emissions per unit of GDP; the other is market policy tool (denoted as P2) is expressed by the ratio of the investment in industrial pollution control to the total industrial output value.

\subsubsection{Control variables}

Population (denoted as R), technological innovation input (denoted as I), industrial structure (denoted as S), and trade dependence (denoted as $\mathrm{M}$ ) as control variables.

\subsection{Model construction}

In order to analysis the impact of different carbon emission reduction policy tools on economic growth, I select panel data models of 30 provinces in China, and constructs the specific model as following:

$$
\ln G=\alpha \ln P_{1}+\beta \ln P_{2}+\gamma \text { Controls }+\varepsilon
$$

\section{Empirical analysis}

\subsection{Descriptive Statistics}

The dependent variable: GDP per capita shows that the economics of China's provinces is increasing year by year, but there are large differences between regions. The economic development of the east is significantly higher than other regions.

Mandatory policy tools are represented by carbon emissions per unit of GDP. It can be seen from the descriptive statistical results that there is a large difference between the maximum and minimum total 
carbon emissions per unit of GDP in China, indicating that China's carbon emissions vary significantly among provinces. After China has promoted the development of a green and low-carbon economy, the carbon emissions per unit GDP of various provinces have been slowly decreasing.

The maximum value of market policy tools is 0.017 , and the minimum value is 0.001 . Both the difference and the average value are relatively small, indicating that China's market carbon emission reduction mechanism is not very different between provinces. The values in all provinces are relatively small, and China still needs to increase investment in industrial pollution control and make full use of market mechanisms to promote carbon emissions reduction.

\subsection{Benchmark regression result}

Table 1. Benchmark regression result

\begin{tabular}{|c|c|}
\hline Variables & $\ln G$ \\
\hline $\ln \mathrm{P} 1$ & $\begin{array}{l}-0.557 * * * \\
(-8.11)\end{array}$ \\
\hline $\ln \mathrm{P} 2$ & $\begin{array}{l}0.069^{* * *} \\
(3.90)\end{array}$ \\
\hline $\operatorname{lnI}$ & $\begin{array}{l}0.379 * * * \\
(5.30)\end{array}$ \\
\hline $\ln S$ & $\begin{array}{l}0.135 \\
(0.90)\end{array}$ \\
\hline $\ln M$ & $\begin{array}{l}-0.037^{*} \\
(-1.93)\end{array}$ \\
\hline $\ln R$ & $\begin{array}{l}-0.172 * * * \\
(-2.75)\end{array}$ \\
\hline Constant & $\begin{array}{l}3.111 * * * \\
(8.57)\end{array}$ \\
\hline Observations & 300 \\
\hline R-squared & 0.447 \\
\hline $\mathrm{F}$ & 306.75 \\
\hline
\end{tabular}

The benchmark regression results of the model are shown in Table 1. It can be seen from the regression results that the coefficient of mandatory policy tools is significantly negative at the $1 \%$ level, indicating that mandatory policy tools have a negative impact on economic growth, verifying Hypothesis H1. The coefficient of market policy tools is positive and significant at the $1 \%$ significance level, indicating that the use of market policy tools in China's provinces has played a role in promoting economic growth, and supports the hypothesis $\mathrm{H} 2$.

\subsection{Robustness test}

The dependent variable economic growth is represented by the per capita GDP replaced by the regional GDP. The results show that the regression coefficient of the mandatory policy tool is significantly negative at the $1 \%$ significance level after economic growth is taken as the proxy variable of the total regional GDP; the coefficient of the market policy tool is also significant at the $1 \%$ significance level and positively correlated with economic growth. It shows that mandatory policy tools inhibit economic growth, while market policy tools effectively promote economic growth, supporting the original conclusion.

\subsection{Further analysis}

\subsubsection{Policy effects}

In 2013, building a national carbon market has become one of the important tasks for comprehensively deepening reform. From June 2013 to June 2014, seven pilot carbon markets were established and began substantial transactions. The pilot regions are required to actively explore the benefits of energy conservation, emission reduction and the development of low-carbon industries. In December 2014, the state promulgated measures for the Administration of Carbon Emissions Trading to guide the development of the carbon market.

So, I select the policy time point in 2013 as the node, and divide the sample into two stages. Specifically, 2010-2013 and 2014-2019, to analysis the impact of market policies on economic growth before and after the policy is released. The regression result is shown in the table 2.

Table 2. Analysis of Policy Effects

\begin{tabular}{|c|c|c|}
\hline \multirow{2}{*}{ Variables } & (1) & (2) \\
\hline & $2010-2013$ & $2014-2019$ \\
\hline \multirow[t]{2}{*}{$\ln \mathrm{P} 1$} & $-0.944 * * *$ & $-0.107^{*}$ \\
\hline & $(-10.02)$ & $(-1.92)$ \\
\hline \multirow[t]{2}{*}{$\ln \mathrm{P} 2$} & 0.009 & $0.105^{* *}$ \\
\hline & $(0.40)$ & $(2.05)$ \\
\hline \multirow[t]{2}{*}{$\ln I$} & $0.397 * *$ & $0.363^{* * *}$ \\
\hline & $(2.61)$ & $(6.34)$ \\
\hline \multirow[t]{2}{*}{$\operatorname{lnS}$} & 0.496 & $0.267 * *$ \\
\hline & $(1.56)$ & $(2.11)$ \\
\hline \multirow[t]{2}{*}{$\ln M$} & $-0.102 * * *$ & $0.075^{* * *}$ \\
\hline & $(-3.85)$ & $(4.65)$ \\
\hline \multirow[t]{2}{*}{$\ln R$} & 0.687 & $-0.188 * * *$ \\
\hline & $(0.85)$ & $(-4.63)$ \\
\hline \multirow[t]{2}{*}{ Constant } & $3.634 * * *$ & $4.010 * * *$ \\
\hline & $(3.63)$ & (10.62) \\
\hline Observations & 120 & 180 \\
\hline R-squared & 0.996 & 0.688 \\
\hline $\mathrm{F}$ & 45.86 & 33.48 \\
\hline
\end{tabular}

It can be seen from the results in the table 2 that there is a positive correlation between the market-based policy tools before the policy issuance and economic growth, but the coefficient is not significant. After the release of relevant policies in 2013, the coefficients of market policy tools were significant at the $5 \%$ level of significance, and showed a positive correlation with economic growth. It shows that after the issuance of market policies, China has developed a carbon market to form a carbon price mechanism covering key industries, and conducts transmission through the market, which is 
conducive to promoting the formation of a market for environmental factors, promoting the gradual formation of carbon price awareness in the whole society, improving technological innovation and technology application for energy saving and carbon reduction. And on this basis, improve carbon productivity, and foster the transformation of China's green and low-carbon development.

\subsubsection{Regional heterogeneity}

China has the characteristics of regional economic level and uneven distribution of energy consumption. Therefore, the effects of energy conservation and emission reduction are often heterogeneous at the regional level. According to the classification standards of the National Bureau of Statistics, China is divided into eastern, central and western regions.

The mandatory policy tools are all negatively significant at the $1 \%$ significance level, indicating that the impact of the three regional mandatory policy tools on economic growth is consistent with the benchmark result.

The coefficients of market policy tools in the eastern region and western region are significant at the significance levels of $1 \%$ and $10 \%$, and both are positive, but not significant in the central region. It shows that after the implementation of market-based policy tools for the carbon emission trading mechanism in the eastern and western regions of China to promote economic growth, enterprises and governments voluntarily reduce emissions. Then, minimize emission reduction costs and effectively develop low carbon economic. But the market policy tools in the central region have no obvious impact on the economic growth of this region. This may be due to the slower development of the carbon emission trading rights market than in the east and west, and the market-based policy tools have not yet taken advantage of the market-based trading mechanism. Therefore, the promotion of economic growth has not been shown.

\section{Conclusions and recommendations}

\subsection{Conclusions}

Based on the panel data of 30 provinces in China from 2010 to 2019 and establish a model to study the impact of carbon emission reduction policies on economic growth, then draws the following conclusions:

From the full sample empirical results of all provinces across the country, the two types of carbon emission reduction policies have different effects on economic growth: mandatory policy tools have a restraining effect on economic growth; market policy tools effectively promote economic growth.

After the release of the pilot carbon emissions trading policy in 2013, the market policy tools have had a positive effect on economic growth.

The impact of mandatory policy tools on economic growth, whether in the national sample or the samples in three regions, shows a negative correlation. There is regional heterogeneity between market policy tools and economic growth, which in the eastern and western regions have a significant effect on economic growth, but have no effect on improving the economic strength of the central region.

\subsection{Recommendations}

China can establish a carbon emission reduction policy based on market policy tools and continue to develop the carbon trading market, then strive to achieve the goal of carbon peak in 2030 and carbon neutral by 2060 .

The government should rationally mix and use different types of carbon emission reduction policy tools according to local conditions. Local regulators guide independent innovation to build a low-carbon industrial system and accelerate the transformation and upgrading of industrial structure. Therefore, China can achieve coordinated development of energy conservation, emission reduction and economic growth.

\section{References}

1. OECD, Economic Instruments for Enviromental Management in Developing Countries, Pairs. (1993)

2. Ge Yujie, Sun Hongmei. The financial performance logic of corporate transformation and energy conservation and environmental protection: an empirical study based on high energy consumption and high pollution listed companies[J].China Environmental Protection Industry,2019(06):14-20.

3. Zhang Zhiqiang, Liu Jinping. The impact of emission-reduction policies on ecological efficiency: a city-level empirical study based on NDDFDID [J].Ecological Economy,2020,36(05):65-71.

4. Zhang Guoxing, Zhang Peide, Xiu Jing, Chai Jian. The effectiveness of energy saving and emission reduction policies on industrial structure adjustment and upgrading $[\mathrm{J}]$.China Population- Resources and Environment,2018,28(02):123-133.

5. Ding Lili, Yang Ying, Wang Wei, Wang Zhuo. Does collaborative innovation really help enterprises to save energy and reduce emissions?[J].Operations Research and Management,2020,29(04):230-239. 